\title{
ANALISIS PENGARUH KUALITAS LAYANAN WEBSITE TERHADAP LOYALITAS PELANGGAN E-COMMERCE BUKALAPAK
}

\author{
Dendy Kurniawan ${ }^{1}$, Neilin Nikhlis ${ }^{2}$ \\ ${ }^{1}$ Universitas Sains dan Teknologi Komputer, e-mail: dendy@stekom.ac.id \\ ${ }^{2}$ Universitas Sains dan Teknologi Komputer, e-mail: neilin.nikh@gmail.com
}

\begin{tabular}{|c|c|}
\hline ARTICLE INFO & ABSTRACT \\
\hline $\begin{array}{l}\text { Article history: } \\
\text { Received } 4 \text { Desember } 2020 \\
\text { Received in revised form } 6 \text { Desember } 2020 \\
\text { Accepted } 8 \text { Desember } 2020 \\
\text { Available online } 28 \text { Desember } 2020\end{array}$ & $\begin{array}{l}\text { E-commerce competition in Indonesia makes e- } \\
\text { commerce companies compete to develop strategies } \\
\text { to win the competition. Customer loyalty is an } \\
\text { important factor to lead in the competition. This } \\
\text { research focuses on how much influence website } \\
\text { service quality has on customer loyalty. This } \\
\text { research is also to find out which website quality } \\
\text { factors have the most influence on customer loyalty } \\
\text { with customer satisfaction as a mediating factor. The } \\
\text { factors that influence e-commerce customer loyalty } \\
\text { are analyzed using concepts including the } \\
\text { dimensions of service quality consisting of (physical } \\
\text { evidence, reliability, responsiveness, assurance, } \\
\text { empathy) and Corporate Image as the variable that } \\
\text { influences and Customer Satisfaction as the variable } \\
\text { that is affected. The sample in this study were } 96 \\
\text { respondents. With the sampling method using the } \\
\text { purposive sampling method. The results obtained } \\
\text { that there is a positive and significant influence } \\
\text { between the dimensions of service quality and } \\
\text { company image on customer satisfaction. } \\
\text { Keywords: E-commerce website, Service } \\
\text { Interaction Quality, Customer Satisfaction }\end{array}$ \\
\hline
\end{tabular}

\section{Pendahuluan}

Pesatnya pertumbuhan pengguna internet, disertai dengan munculnya website yang menyediakan berbagai kebutuhan sehari-hari, salah satunya website belanja online (e-commerce). Banyaknya bisnis online yang bermunculan di Indonesia juga disebabkan oleh jumlah pengguna internet yang terus bertambah setiap tahunnya. Iindonesia menempati posisi kelima secara global, mencapai 190,92 juta pengguna dengan pertumbuhan hingga 20\% [1]. Internet digunakan di berbagai gadget, seperti smartphone, laptop, komputer pribadi, dan perangkat lainnya sehingga mendorong perilaku konsumtif melalui internet. Nilai penjualan ritel e-commerce di Indonesia meningkat hingga $21 \%$ setiap tahunnya dan diprediksi akan terus meningkat [2].

Selain itu pandemi Covid-19 membuat masyarakat Indonesia untuk melakukan kegiatan sehari - hari di rumah, baik bekerja, beribadah, sekolah serta kegiatan baik formal atau nonformal lainnya. Berbelanja dari rumah (online shopping) menjadi opsi masyarakat untuk melakukan perbelanjaan ditengah aturan PSBB yang ketat, hal ini dibuktikan dengan naiknya persentase belanja online di Indonesia selama pandemi sebesar 400\% menurut CNN Indonesia [3]. Hal ini 
menjadi peluang bagi para pelaku e-commerce untuk membuka usahanya di Indonesia, termasuk website Bukalapak.

Bukalapak adalah perusahaan teknologi Indonesia yang memiliki misi menciptakan perekonomian yang adil untuk semua. Melalui platform online dan offlinenya, Bukalapak memberikan kesempatan dan pilihan kepada semua orang untuk meraih hidup yang lebih baik. Berdasarkan data top 10 E-commerce di Indonesia pada Q1 tahun 2020, markerplace yang paling banyak di kunjungi pada urutan pertama adalah shopee dengan jumlah 71.530.000. Pada posisi ke dua di tempati marketplace tokopedia dengan jumlah pengunjung 69.800.000 dan disusul di posisi ke tiga yaitu bukalapak dengan total pengunjung 37.630.000. Data ini dapat di lahat pada gambar 1 di bawah.

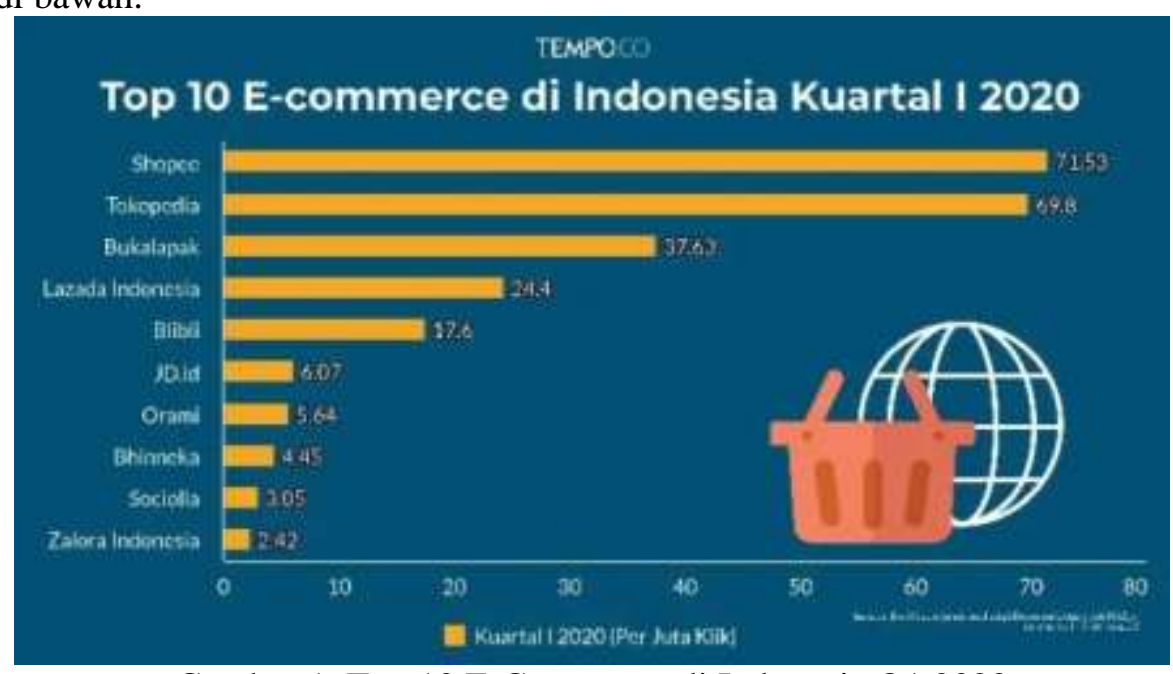

Gambar 1. Top 10 E-Commerce di Indonesia Q1 2020

(Sumber : statik.tempo.co)

Bukalapak Indonesia telah menyiapkan beberapa strategi untuk bersaing di pasar ecommerce Indonesia, salah satunya adalah membangun pengalaman pelanggan. Selain membangun pengalaman pelanggan, Bukalapak memiliki ide untuk meningkatkan kualitas situs web dengan menambahkan beberapa aspek baru yang tidak dimiliki pesaingnya. Hal ini menunjukkan bahwa Bukalapak menyadari bahwa kualitas website merupakan salah satu faktor utama kepuasan pelanggan [4]. Kotrler dan Armstrong (2012:681) [5] menyatakan bahwa kualitas layanan adalah keseluruhan dari keistimewaan dan karakteristik dari produk atau jasa yang menunjang kemampuanya untuk memuaskan kebutuhan secara langsung maupun tidak langsung. Hal ini berarti badan usaha harus dapat memberikan produk atau layanan yang dapat memenuhi kebutuhan pelanggan agar pelanggan akan merasa puas. Secara ideal menurut pemikiran yang dikembangkan Parasuraman et al. (1998) dalam Lupiyoadi dan Handani (2011:148) [6] mendefinisikan bahwa service quality sebagai seberapa jauh perbedaan antara kenyataan dan harapan pelanggan atas layanan yang mereka terima/peroleh. Terdapat lima dimensi service quality yaitu (1) tangibles (2) reliability (3) responsivenes (4) assurance (5) empathy.

Penelitian ini juga dilakukan untuk mengidentifikasi pengaruh kualitas website terhadap loyalitas pelanggan dengan kepuasan pelanggan sebagai faktor mediasi di sektor ritel online. Dengan demikian, penelitian ini dapat membantu pengecer online yang ada dan yang baru berdiri untuk menyadari pentingnya kualitas situs web dalam bisnis online untuk memenangkan persaingan. Hal ini dapat meningkatkan kinerja situs web dengan memahami bagian mana dari situs web Bukalapak yang perlu ditingkatkan.

Analisis Pengaruh Kualitas Layanan Website Terhadap Loyalitas Pelanggan E-Commerce Bukalapak (Dendy Kurniawan) 


\section{Landasan Teori}

\subsection{Kepuasan Pelanggan}

Kepuasan pelanggan adalah perasaan puas atau kecewa setelah membandingkan harapan dengan kenyataan yang diperoleh. Kepuasan atau kesenangan yang tinggi menciptakan ikatan emosional terhadap merek atau perusahaan tertentu. Berdasarkan pendapat tersebut dapat dikatakan bahwa kepuasan pelanggan erat kaitannya dengan dua hal, harapan dan hasil yang diterima. Kepuasan pelanggan adalah kesesuaian antara harapan dan persepsi atas pelayanan yang diterima (hasil yang diperoleh atau kenyataan yang dialami). Kepuasan pelanggan tercipta selama periode pembelian, pengalaman menggunakan produk atau layanan, dan periode setelah pembelian. Pelanggan yang puas dengan produk yang mereka gunakan akan kembali menggunakan produk yang ditawarkan. Hasil kepuasan pelanggan merupakan salah satu faktor terpenting untuk memenangkan persaingan [7].

Peningkatan kepuasan pelanggan dapat memberikan manfaat perusahaan seperti loyalitas pelanggan, memperpanjang siklus hidup pelanggan, memperpanjang umur barang dagangan yang dibeli pelanggan, dan meningkatkan komunikasi positif dari mulut ke mulut pelanggan. Ketika pelanggan puas dengan produk atau layanan perusahaan, pelanggan akan sering membeli produk atau layanan dan merekomendasikannya kepada pelanggan potensial. Tidak mungkin suatu organisasi bisnis dapat berkembang jika perusahaan mengabaikan atau mengabaikan kebutuhan pelanggan[8].

\subsection{Loyalitas Pelanggan}

Loyalitas adalah perilaku konsumen yang melakukan perilaku pembelian, yang didefinisikan sebagai pembelian tidak acak yang diungkapkan dari waktu ke waktu oleh beberapa unit pengambilan keputusan. Pelanggan yang loyal memiliki prasangka tertentu tentang apa yang ingin mereka beli berulang kali [9].

Ciri-ciri pelanggan setia adalah melakukan pembelian ulang secara teratur, membeli lini produk dan jasa, memberikan referensi kepada orang lain, dan menunjukkan kekebalan dari daya tarik pesaing.

Menurut pemikiran yang dikembangkan oleh Zeithaml et al dalam Yoga Saputra, dan Retno Setyorini, ST., MM. (2015) [10], kualitas pelayanan memiliki lima dimensi pengukuran yaitu :

\section{a. Bukti Fisik (Tangible)}

Tangible (bentuk fisik), yaitu berupa penampilan fisik web, kesesuaian, dan konten - konten yang baik. Memberikan representasi fisik dari layanan kepada konsumen, terutama konsumen baru, yang akan digunakan untuk mengevaluasi kualitas. Termasuk di dalamnya adalah cara penggunaan aplikasi yang mudah dan nyaman.

\section{b. Keandalan (Reliability)}

Menurut Zeithaml et al dalam Yoga Saputra, dan Retno Setyorini, ST., MM. (2015) [10], Reliability (keandalan), yaitu berupa kemampuan untuk melakukan layanan yang dijanjikan dapat dipercaya dan akurat. Dalam arti luas, keandalan berarti bahwa perusahaan atau pelapak memberikan janji-janji mengenai produk yang di jual, penyediaan layanan online 24 jam, penyelesaian masalah online, dan berkaitan dengan harga. Hal ini menjadikan para pelapak bisa menjual barang produk atau jasa tanpa harus memikirkan biaya administrasi dari bukalapak.

\section{c. Ketanggapan (Responsive)}

Menurut Parasuraman dalam Ratnasari dan Aksa (2011:107) [11], Responsiveness (ketanggapan) adalah kemauan untuk membantu dan memberikan pelayanan yang responsive dan tepat kepada pelanggan, dengan penyampaian informasi yang tepat jelas. Karena membiarkan bug atau error dalam waktu yang lama 
menyebabkan persepsi yang negatif dalam kualitas dari konsumen. Apalagi saat pelanggan sudah membayar transaksinya namun pelapak tidak sesegera mungkin mengemas atau mengirim produk yang dijual.

\section{d. Jaminan (Asurance)}

Jaminan dapat diartikan sebagai tanggung jawab dari pekerjaan yang telah dilakukan perusahaan kepada pelanggan. Sejauh mana perusahaan memberikan jaminan kepada konsumen jika barang yang di beli mengalami kerusakan, ketidak sesuaian atau bahkan barang yang telah di bayar nampaknya tidak di kirim oleh penjual.

\section{e. Empati}

Menurut Zeithaml et al (2009:111) dalam Yoga Saputra, dan Retno Setyorini, ST., MM. (2015) [10], Empati merupakan memberikan perhatian yang tulus dan bersifat individual atau pribadi yang diberikan kepada para konsumen dengan berupaya memahami keinginan konsumen. Dimana website diharapkan memberikan informasi informasi yang tepat disaat konsumen mengalami kesulitan atau ke tidak tahuan tentang penggunaan website tersebut. Dan memberikan pelayanan yang baik ketika konsumen sedang komplain atau pengaduan berkaitan dengan layanan yang di berikan.

\section{f. Citra Perusahaan}

Citra (image)merupakan gambaran yang ada dalam benak publik tentang perusahaan. Citra adalah persepsi publik tentang perusahaan menyangkut pelayananya, kemudahan, jaminan, perilaku perusahaan dan lainya. Pada akhirnya persepsi akan mempengaruhi sikap publik apakah mendukung, netral atau memusuhi (Kriyantono, 2008:9) [12].

\section{Metode Penelitian}

Metode penelitian yang digunakan dalam penelitian ini adalah penelitian kuantitatif dengan responden masyarakat umum di kota Kendal dengan usia 18 samapai dengan 50 tahun. Pengambilan sampel menggunakan metode purposive sampling dimana sampel tersebut minimal pernah mengunjungi web bukalapak sebanyak satu kali. Dan didapat jumlah sampel sebanyak 96 orang yang bersedia mengisi kuisioner yang telah di sediakan.

Pengukuran yang digunakan dalam penelitian ini adalah skala pengukuran yang bersifat interval dengan menggunakan skala Likert. Dengan keterangan nilai 1 (Sangat Tidak Setuju), nilai 2 (Tidak Setuju), nilai 3 (Netral), nilai 4 (Setuju), nilai 5 (Sangat Setuju)

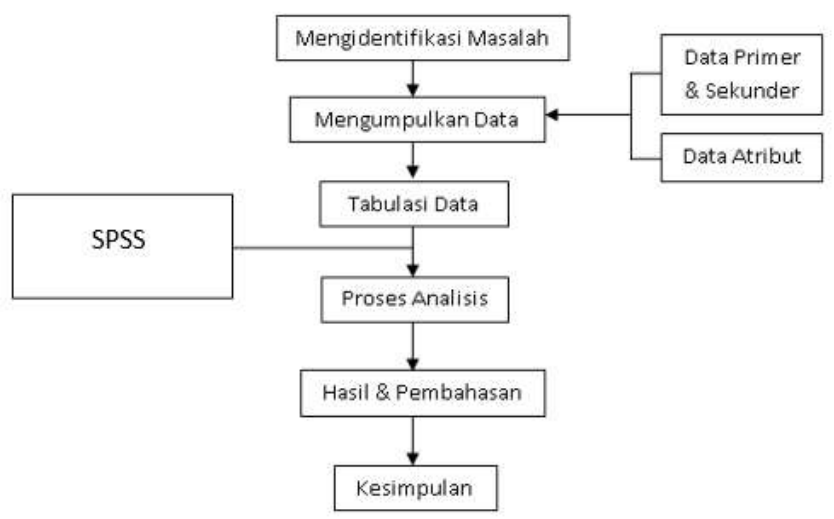

Gambar 2. Tahap Penelitian 
4. Hasil dan Analisis

\subsection{Deskripsi Responden Berdasarkan Jenis Kelamin}

Berdasarkan tabel 4.1 di bawah terlihat bahwa responden berjenis kelamin laki-laki sebanyak 63 orang, sedangkan responden berjenis kelamin perempuan sebanyak 33 orang.

Tabel 4.1

Jenis Kelamin Responden

\begin{tabular}{|c|c|c|c|}
\hline No & Jenis Kelamin & Frekuensi & Presentase \\
\hline 1. & Laki-laki & 63 & $65,6 \%$ \\
\hline 2. & Perempuan & 33 & $34,4 \%$ \\
\hline \multicolumn{2}{|c|}{ Jumlah } & 96 & $100 \%$ \\
\hline
\end{tabular}

Sumber : Data Primer yang diolah, 2020

\subsection{Deskripsi Responden Berdasarkan Usia}

Tabel 4.2

Usia Responden

\begin{tabular}{|c|c|c|c|}
\hline No. & Umur & Frekuensi & Presentase \\
\hline 1. & $18-22$ Tahun & 9 & $9,3 \%$ \\
\hline 2. & $23-27$ Tahun & 17 & $17,7 \%$ \\
\hline 3. & $28-32$ Tahun & 22 & $22,9 \%$ \\
\hline 4. & $33-37$ Tahun & 19 & $19,8 \%$ \\
\hline 5. & $38-42$ Tahun & 12 & $12.5 \%$ \\
\hline 6. & $43-47$ Tahun & 10 & $10,4 \%$ \\
\hline 7. & $48-50$ Tahun & 7 & $7,3, \%$ \\
\hline \multicolumn{2}{|r|}{ Jumlah } & 96 & $100 \%$ \\
\hline
\end{tabular}

Sumber : Data Primer yang diolah, 2020

Berdasarkan tabel 4.2 diatas, menunjukan bahwa responden dengan usia 28 - 32 tahun yaitu sebesar 22,9\% dan juga di usia 33 - 37 tahun sebesar 19,8\%.

\subsection{Deskripsi Responden Berdasarkan Pekerjaan}

Tabel 4.3

Responden Berdasarkan Pekerjaan

\begin{tabular}{|c|c|c|c|}
\hline No. & Pekerjaan & Frekuensi & Presentase \\
\hline 1. & Pegawai & 16 & $16,7 \%$ \\
\hline 2. & Wiraswasta & 20 & $20,8 \%$ \\
\hline 3. & Buruh & 38 & $39,6 \%$ \\
\hline 4. & Mahasiswa/Pelajar & 9 & $9,4 \%$ \\
\hline 5. & Lain-lain & 13 & $13,5 \%$ \\
\hline \multicolumn{2}{|c|}{ Jumlah } & 96 & $100 \%$ \\
\hline
\end{tabular}

Sumber : Data Primer yang diolah, 2020

Tabel 4.3 menunjukan bahwa responden yang bekerja sebagai pegawai ada 16 orang, responden yang bekerja sebagai wiraswasta sebanyak 20orang, responden yang bekerja sebagai buruh 38 orang, responden yang masih dudk di bangku pendidikan sebanyak 9 orang.

JURNAL ILMIAH ELEKTRONIKA DAN KOMPUTER Vol. 13, No. 2, Desember $2020: 158-168$ 


\subsection{Deskripsi Responden Melakukan Kunjungan Web Bukalapak}

Tabel 4.4

\section{Distribusi Berdasarkan Responden Melakukan Kunjungan Web}

\begin{tabular}{|c|c|c|c|}
\hline No. & Melakukan Servis & Frekuensi & presentase \\
\hline 1. & $3 \mathrm{x}$ & 33 & $34,4 \%$ \\
\hline 2. & $>3 \mathrm{x},<10 \mathrm{x}$ & 45 & $46,9 \%$ \\
\hline 3. & $>10 \mathrm{x}$ & 18 & $18,7 \%$ \\
\hline \multicolumn{2}{|c|}{ Jumlah } & 96 & $100 \%$ \\
\hline
\end{tabular}

Sumber : Data Primer yang Diolah, 2020

Tabel 4.4 menunjukan berapa kali responden melakukan kunjungan pada web Bukalapak. Dimana responden yang telah melakukan kunjungan bukalapak 3x sebanyak 33 orang, responden yang telah melakukan kunjungan bukalapak lebih dari 3x yakni 45orang, dan responden yang melakukan kunjungan bukalapak lebih dari 10x hanya 18 orang.

\subsection{Analisis Deskriptif Variabel Bukti Fisik}

\section{Tabel 4.5}

Hasil Jawaban Indikator Bukti Fisik

\begin{tabular}{|c|c|c|c|c|c|c|c|c|c|c|c|c|c|c|}
\hline \multirow[t]{2}{*}{ No. } & \multirow[t]{2}{*}{ Indikator } & \multicolumn{2}{|c|}{ STS (1) } & \multicolumn{2}{|c|}{ TS (2) } & \multicolumn{2}{|c|}{$\mathrm{N}(3)$} & \multicolumn{2}{|c|}{ S (4) } & \multicolumn{2}{|c|}{ SS (5) } & \multirow{2}{*}{$\begin{array}{l}\mathrm{Jm} \\
1\end{array}$} & \multirow[t]{2}{*}{ Skor } & \multirow{2}{*}{$\begin{array}{l}\text { Rata } \\
\text {-rata }\end{array}$} \\
\hline & & $\mathrm{F}$ & $\begin{array}{l}\text { Fx } \\
S\end{array}$ & $\mathrm{~F}$ & $\begin{array}{l}\mathrm{F} \\
\mathrm{Xs}\end{array}$ & $F$ & fxs & $\mathrm{F}$ & $\begin{array}{l}\text { Fx } \\
S\end{array}$ & $F$ & Fxs & & & \\
\hline 1. & $\begin{array}{l}\text { Fasilitas } \\
\text { Website }\end{array}$ & 0 & 0 & 31 & 62 & 40 & 120 & 23 & 92 & 2 & 10 & 96 & 284 & 3 \\
\hline 2. & $\begin{array}{l}\text { Teknologi } \\
\text { website } \\
\text { digunakan }\end{array}$ & 1 & 1 & 5 & 10 & 30 & 90 & 39 & 156 & 21 & 105 & 96 & 362 & 3,8 \\
\hline 3. & $\begin{array}{l}\text { Penampil } \\
\text { an } \\
\text { Website }\end{array}$ & 0 & 0 & 7 & 14 & 39 & 117 & 37 & 148 & 13 & 65 & 96 & 344 & 3,7 \\
\hline Rat: & rata & & & & & & & & & & & & & 3,5 \\
\hline
\end{tabular}

Sumber : Data Primer yang diolah, 2020

Berdasarkan data yang diperoleh secara keseluruhan dapat diketahui bahwa responden telah mempersepsikan baik kepuasan pelanggan terhadap website ecommerce Bukalapak. Hal ini dibuktikan dengan perolehan nilai rata-rata untuk variabel bukti fisik, yakni 3,5. Artinya responden menjawab setuju untuk tiap-tiap indikator yang mengukur variabel bukti fisik.

\subsection{Analisis Deskriptif Variabel Keandalan}

Tabel 4.6

Hasil Jawaban Indikator Keandalan

\begin{tabular}{|c|c|c|c|c|c|c|c|c|c|c|c|c|c|c|}
\hline \multirow[t]{2}{*}{ No. } & \multirow[t]{2}{*}{ Indikator } & \multicolumn{2}{|c|}{$\begin{array}{c}\text { STS } \\
(1)\end{array}$} & \multicolumn{2}{|c|}{$\operatorname{TS}(2)$} & \multicolumn{2}{|c|}{$\mathrm{N}(3)$} & \multicolumn{2}{|c|}{ S (4) } & \multicolumn{2}{|c|}{ SS (5) } & \multirow[t]{2}{*}{$\mathrm{Jml}$} & \multirow[t]{2}{*}{ Skor } & \multirow{2}{*}{$\begin{array}{l}\text { Rat } \\
\text { a- } \\
\text { rata }\end{array}$} \\
\hline & & $\mathrm{F}$ & $\begin{array}{l}\text { F } \\
x s\end{array}$ & $\mathrm{~F}$ & $\begin{array}{l}\text { Fx } \\
\text { S }\end{array}$ & $\mathrm{F}$ & Fxs & $\mathrm{F}$ & Fxs & $\mathrm{F}$ & Fxs & & & \\
\hline 1. & $\begin{array}{l}\text { Ketepatan } \\
\text { waktu } \\
\text { pelayanan }\end{array}$ & 1 & 1 & 19 & 38 & 35 & 105 & 36 & 144 & 5 & 25 & 96 & 313 & 3,3 \\
\hline
\end{tabular}

Analisis Pengaruh Kualitas Layanan Website Terhadap Loyalitas Pelanggan E-Commerce 


\begin{tabular}{|c|l|l|l|l|l|l|l|l|l|l|l|l|l|l|}
\hline 2. & $\begin{array}{l}\text { Keandala } \\
\text { n pelapak }\end{array}$ & 0 & 0 & 3 & 6 & 48 & 144 & 40 & 160 & 5 & 25 & 96 & 335 & 3,5 \\
\hline $\begin{array}{l}\text { Hasil } \\
\text { transaksi } \\
\text { 3ang baik } \\
\text { dan } \\
\text { memuask } \\
\text { an }\end{array}$ & 0 & 0 & 4 & 8 & 34 & 102 & 44 & 176 & 14 & 70 & 96 & 356 & 3,8 \\
\hline
\end{tabular}

Sumber : Data Primer yang diolah, 2020

Berdasarkan data yang diperoleh secara keseluruhan dapat diketahui bahwa perolehan nilai rata-rata untuk variabel keandalan yaitu 3,5. Artinya responden menjawab setuju untuk tiaptiap indikator yang mengukur variabel kehandalan dalam melayani. Dari hasil perhitungan diketahui bahwa indikator hasil transaksi jual beli dikatakan baik dan memuaskan memiliki nilai rata-rata tertinggi dibandingkan indikator yang lainya. Hasil ini menunjukan bahwa pelapak Bukalapak memiliki kehandalan dalam pelayanan yang membuat pelanggan puas dengan hasil yang diberikan.

\subsection{Analisis Deskriptif Variabel Ketanggapan}

\section{Tabel 4.7}

Hasil Jawaban Indikator Ketanggapan

\begin{tabular}{|c|c|c|c|c|c|c|c|c|c|c|c|c|c|c|}
\hline \multirow[t]{2}{*}{ No. } & \multirow[t]{2}{*}{ Indikator } & \multicolumn{2}{|c|}{$\begin{array}{l}\text { STS } \\
(1)\end{array}$} & \multicolumn{2}{|c|}{ TS (2) } & \multicolumn{2}{|c|}{$\mathrm{N}(3)$} & \multicolumn{2}{|c|}{ S (4) } & \multicolumn{2}{|c|}{ SS (5) } & \multirow[t]{2}{*}{$\mathrm{Jml}$} & \multirow[t]{2}{*}{ Skor } & \multirow{2}{*}{$\begin{array}{l}\text { Rat } \\
\text { a- } \\
\text { rata }\end{array}$} \\
\hline & & $\mathrm{F}$ & $\begin{array}{l}\mathrm{fx} \\
\mathrm{s}\end{array}$ & $\mathrm{F}$ & Fxs & $\mathrm{F}$ & Fxs & $\mathrm{F}$ & Fxs & $\mathrm{F}$ & Fxs & & & \\
\hline 1. & $\begin{array}{l}\text { Pengetahu } \\
\text { an } \\
\text { pelapak }\end{array}$ & 1 & 1 & 4 & 8 & 43 & 129 & 43 & 172 & 5 & 25 & 96 & 335 & 3,5 \\
\hline 2. & $\begin{array}{l}\text { Cepat } \\
\text { dalam } \\
\text { menganga } \\
\text { ni } \\
\text { pesanan } \\
\text { dan } \\
\text { keluhan } \\
\end{array}$ & 0 & 0 & 9 & 18 & 42 & 126 & 39 & 156 & 6 & 30 & 96 & 330 & 3,4 \\
\hline 3. & $\begin{array}{l}\text { Cepat } \\
\text { dalam } \\
\text { menyeles } \\
\text { aikan } \\
\text { masalah }\end{array}$ & 1 & 1 & 11 & 22 & 44 & 132 & 32 & 128 & 8 & 40 & 96 & 323 & 3,4 \\
\hline Rata & rata & & & & & & & & & & & & & 3,4 \\
\hline
\end{tabular}

Sumber : Data Primer yang diolah, 2020

Berdasarkan data yang diperoleh secara keseluruhan dapat diketahui bahwa perolehan nilai rata-rata untuk variabel ketanggapan, yakni 3,4. Artinya responden menjawab setuju untuk tiap-tiap indikator yang mengukur variabel ketanggapan dalam pelayanan dengan pemberian respon memproses barang atau jasa yang telah di beli oleh pelangganya.

JURNAL ILMIAH ELEKTRONIKA DAN KOMPUTER Vol. 13, No. 2, Desember $2020: 158-168$ 


\subsection{Analisis Deskriptif Variabel Jaminan}

Tabel 4.8

Hasil Jawaban Indikator Jaminan

\begin{tabular}{|c|c|c|c|c|c|c|c|c|c|c|c|c|c|c|}
\hline \multirow[t]{2}{*}{$\begin{array}{l}\text { No } \\
\text {. }\end{array}$} & \multirow[t]{2}{*}{ Indikator } & \multicolumn{2}{|c|}{$\begin{array}{c}\text { STS } \\
\text { (1) }\end{array}$} & \multicolumn{2}{|c|}{ TS (2) } & \multicolumn{2}{|c|}{$\mathrm{N}(3)$} & \multicolumn{2}{|c|}{ S (4) } & \multicolumn{2}{|c|}{ SS (5) } & \multirow[t]{2}{*}{$\mathrm{Jml}$} & \multirow[t]{2}{*}{ Skor } & \multirow[t]{2}{*}{$\begin{array}{l}\text { Rata- } \\
\text { rata }\end{array}$} \\
\hline & & $\mathrm{F}$ & fXs & $\mathrm{F}$ & Fxs & $\mathrm{F}$ & Fxs & $\mathrm{F}$ & Fxs & $F$ & Fxs & & & \\
\hline 1. & $\begin{array}{l}\text { Pelapak } \\
\text { Bukalapak } \\
\text { memberika } \\
\text { n jaminan } \\
\text { garansi }\end{array}$ & 0 & 0 & 5 & 10 & 25 & 75 & 53 & 212 & 13 & 65 & 96 & 362 & 3,8 \\
\hline 2. & $\begin{array}{l}\text { Pelapak } \\
\text { Bukalapak } \\
\text { dapat } \\
\text { dipercaya }\end{array}$ & 0 & 0 & 6 & 12 & 31 & 93 & 37 & 148 & 22 & 110 & 96 & 363 & 3,8 \\
\hline 3. & $\begin{array}{l}\text { Kesopanan } \\
\text { Pelapak } \\
\text { Bukalapak }\end{array}$ & 0 & 0 & 4 & 8 & 38 & 114 & 34 & 136 & 20 & 100 & 96 & 358 & 3,7 \\
\hline Ratc & -rata & & & & & & & & & & & & & 3,8 \\
\hline
\end{tabular}

Sumber : Data Primer yang diolah, 2020

Berdasarkan data yang diperoleh secara keseluruhan dapat diketahui bahwa perolehan nilai rata-rata untuk variabel jaminan, yakni 3,8. Artinya responden menjawab setuju untuk tiaptiap indikator yang mengukur variabel ketanggapan baik dalam melayani. Dari hasil perhitungan diketahui bahwa perusahaan telah memberikan bimbingan kepada pelapak supaya pelapak dapat melayani dengan baik dengan memberikan jaminan garansi sehingga perusahaan tersebut benarbenar bisa diprcaya dengan baik.

\subsection{Analisis Deskriptif Variabel Empati}

Tabel 4.9

Hasil Jawaban Indikator Empati

\begin{tabular}{|c|c|c|c|c|c|c|c|c|c|c|c|c|c|c|}
\hline \multirow[t]{2}{*}{$\begin{array}{l}\mathrm{N} \\
\mathrm{o} .\end{array}$} & \multirow[t]{2}{*}{ Indikator } & \multicolumn{2}{|c|}{$\begin{array}{l}\text { STS } \\
\text { (1) }\end{array}$} & \multicolumn{2}{|c|}{ TS (2) } & \multicolumn{2}{|c|}{$\mathrm{N}(3)$} & \multicolumn{2}{|c|}{ S (4) } & \multicolumn{2}{|c|}{ SS (5) } & \multirow[t]{2}{*}{$\mathrm{Jml}$} & \multirow[t]{2}{*}{ Skor } & \multirow[t]{2}{*}{$\begin{array}{l}\text { Rata- } \\
\text { rata }\end{array}$} \\
\hline & & $\mathrm{F}$ & fxs & $\mathrm{F}$ & Fxs & $\mathrm{F}$ & Fxs & $\mathrm{F}$ & fxs & $\mathrm{F}$ & Fxs & & & \\
\hline 1. & $\begin{array}{l}\text { Kemudaha } \\
\mathrm{n} \\
\text { komunikas } \\
\text { i kepada } \\
\text { pelanggan }\end{array}$ & 0 & 0 & 1 & 2 & 34 & 102 & 48 & 192 & 13 & 65 & 96 & 361 & 3,8 \\
\hline 2. & $\begin{array}{l}\text { Pelayanan } \\
\text { yang adil }\end{array}$ & 0 & 0 & 7 & 14 & 48 & 144 & 37 & 148 & 4 & 20 & 96 & 326 & 3,4 \\
\hline 3. & $\begin{array}{l}\text { Memberika } \\
\mathrm{n} \text { informasi } \\
\text { mengenai } \\
\text { jadwal } \\
\text { penangana } \\
\mathrm{n} \text { pesanan }\end{array}$ & 0 & 0 & 9 & 18 & 28 & 84 & 50 & 200 & 9 & 45 & 96 & 347 & 3,6 \\
\hline $\mathrm{Ra}$ & -rata & & & & & & & & & & & & & 3,6 \\
\hline
\end{tabular}

Sumber : Data Primer yang diolah, 2020

Analisis Pengaruh Kualitas Layanan Website Terhadap Loyalitas Pelanggan E-Commerce 
Berdasarkan data yang diperoleh secara keseluruhan dapat diketahui bahwa perolehan nilai rata-rata untuk variabel empati, yakni 3,6. Artinya responden menjawab setuju untuk tiaptiap indikator yang mengukur variabel ketanggapan baik dalam melayani. Dari hasil perhitungan diketahui bahwa indikator kemudahan dalam berkomunikasi memiliki nilai rata-rata tertinggi dibandingkan indikator yang lainya. Hasil ini menunjukan bahwa adanya rasa empati terhadap pelanggan yang diberikan baik untuk memberikan kepuasan.

\subsection{Analisis Deskriptif Variabel Citra Perusahaan}

Tabel 4.10

Hasil Jawaban Indikator Citra Perusahaan

\begin{tabular}{|c|c|c|c|c|c|c|c|c|c|c|c|c|c|c|}
\hline \multirow[t]{2}{*}{ No } & \multirow[t]{2}{*}{ Indikator } & \multicolumn{2}{|c|}{$\begin{array}{l}\text { STS } \\
\text { (1) }\end{array}$} & \multicolumn{2}{|c|}{ TS (2) } & \multicolumn{2}{|c|}{$\mathrm{N}(3)$} & \multicolumn{2}{|c|}{ S (4) } & \multicolumn{2}{|c|}{ SS (5) } & \multirow[t]{2}{*}{ Jml } & \multirow[t]{2}{*}{ Skor } & \multirow{2}{*}{$\begin{array}{l}\text { Rata } \\
\text {-rata }\end{array}$} \\
\hline & & $\mathrm{F}$ & fxs & $\mathrm{F}$ & Fxs & $\mathrm{F}$ & Fxs & $\mathrm{F}$ & fxs & $\mathrm{F}$ & Fxs & & & \\
\hline 1. & $\begin{array}{l}\text { Reputasi } \\
\text { vang baik }\end{array}$ & 0 & 0 & 0 & 0 & 15 & 45 & 53 & 212 & 28 & 140 & 96 & 397 & 4,1 \\
\hline 2. & $\begin{array}{l}\text { Kepercaya } \\
\text { an } \\
\text { perusahaan }\end{array}$ & 0 & 0 & 6 & 12 & 29 & 87 & 40 & 160 & 21 & 105 & 96 & 364 & 3,8 \\
\hline 3. & $\begin{array}{l}\text { Daya tarik } \\
\text { fasilitas } \\
\text { fisik } \\
\text { perusahaan }\end{array}$ & 0 & 0 & 2 & 4 & 22 & 66 & 50 & 200 & 30 & 150 & 96 & 420 & 4,4 \\
\hline $\mathrm{Ra}$ & -rata & & & & & & & & & & & & & 4,2 \\
\hline
\end{tabular}

Sumber : Data Primer yang diolah, 2020

Berdasarkan data yang diperoleh secara keseluruhan dapat diketahui bahwa perolehan nilai rata-rata untuk variabel citra perusahaan, yakni 4,2. Artinya responden menjawab setuju untuk tiap-tiap indikator yang mengukur variabel citra perusahaan terhadap kepuasan pelanggan. Dari hasil perhitungan diketahui bahwa indikator citra perusahaan bukalapak memiliki daya tarik bagi pelanggan untuk melakukan pembelian online memiliki nilai rata-rata tertinggi dibandingkan indikator yang lainya yang dapat memberikan rasa puas kepada pelangganya.

\subsection{Analisis Deskriptif Variabel Kepuasan Pelanggan}

Tabel 4.11

Hasil Jawaban Indikator Kepuasan Pelanggan

\begin{tabular}{|l|l|l|l|l|l|l|l|l|l|l|l|l|l|l|}
\hline No. & Indikator & \multicolumn{2}{|c|}{$\begin{array}{l}\text { STS } \\
(1)\end{array}$} & \multicolumn{2}{|c|}{ TS (2) } & \multicolumn{2}{|c|}{$\mathrm{N}(3)$} & \multicolumn{2}{|c|}{ S (4) } & \multicolumn{2}{|c|}{ SS (5) } & Jml & Skor & $\begin{array}{l}\text { Rat } \\
\text { a- } \\
\text { rata }\end{array}$ \\
\cline { 2 - 13 } & $\begin{array}{l}\text { F } \\
\text { fx } \\
\text { s }\end{array}$ & F & Fxs & F & Fxs & F & fxs & F & Fxs & \\
\hline 1. & $\begin{array}{l}\text { Kesesuaia } \\
\text { n harapan } \\
\text { pelangan }\end{array}$ & 0 & 0 & 1 & 2 & 17 & 51 & 62 & 248 & 16 & 80 & 96 & 381 & 4 \\
\hline 2. & $\begin{array}{l}\text { Minat } \\
\text { berkunjun } \\
\text { g kembali }\end{array}$ & 0 & 0 & 2 & 4 & 43 & 129 & 38 & 152 & 13 & 65 & 96 & 350 & 3,6 \\
\hline
\end{tabular}

JURNAL ILMIAH ELEKTRONIKA DAN KOMPUTER Vol. 13, No. 2, Desember $2020: 158-168$ 


\begin{tabular}{|l|l|l|l|l|l|l|l|l|l|l|l|l|l|l|}
\hline 3. & $\begin{array}{l}\text { Kesediaan } \\
\text { merekom } \\
\text { endasikan } \\
\begin{array}{l}\text { Online } \\
\text { shop }\end{array}\end{array}$ & 0 & 0 & 0 & 0 & 24 & 72 & 47 & 188 & 25 & 125 & 96 & 385 & 4 \\
\hline 4 & $\begin{array}{l}\text { Kesetiaan } \\
\text { akan tetap } \\
\text { berbelanja } \\
\text { pada } \\
\text { bukalapak }\end{array}$ & 0 & 0 & 4 & 8 & 41 & 123 & 46 & 184 & 5 & 25 & 96 & 340 & 3,5 \\
\hline \multicolumn{2}{|l|}{ Rata-rata }
\end{tabular}

Sumber : Data Primer yang diolah, 2020

Berdasarkan data yang diperoleh secara keseluruhan dapat diketahui bahwa perolehan nilai rata-rata untuk variabel kepuasan pelanggan, yakni 3,8. Artinya kepuasan pelanggan dalam melakukan pembelian online di bukalapak dirasa sudah baik. Hal tersebut dibuktikan bahwa indikator harapan sesuai keinginan pelanggan memiliki rata-rata yang tinggi sehingga dapat dipertimbangkan untuk indikator pelanggan bersedia merekomendasikan Bukalapak tersebut kepada orang lain. Dari hasil ini menunjukan bahwa adanya rasa puas dari pelanggan melakukan pembelian online.

\section{Kesimpulan}

Dari pembahasan yang telah diuraikan diatas, serta berdasarkan data yang diperoleh dari penelitian sebagaimana yang telah dibahas pada bab 4, maka dapat ditarik kesimpulan sebagai berikut :

1) Bukti fisik (Tangible) dalam pelayanan berpengaruh positif dan signifikan terhadap kepuasan pelanggan website Bukalapak.

2) Keandalan (Reability) dalam pelayanan berpengaruh positif dan signifikant terhadap kepuasan pelanggan website Bukalapak.

3) Ketanggapan (Responsiveness) dalam pelayanan berpengaruh positif dan signifikan terhadap kepuasan pelanggan website Bukalapak.

4) Jaminan (Assurance) dalam pelayanan berpengaruh positif dan signifikan terhadap kepuasan pelanggan website Bukalapak.

5) Empati (Empathy) dalam pelayanan berpengaruh positif dan signifikan terhadap kepuasan pelanggan website Bukalapak.

6) Citra Perusahaan berpengaruh positif dan signifikan terhadap kepuasan pelanggan website Bukalapak.

\section{References}

[1] Statista, "Number of internet users in Indonesia from 2017 to 2020 | Statista," Statista, 2020. [Online]. Available: https://www.statista.com/statistics/254456/number-of-internet-users-inindonesia/.

[2] Statista, "Indonesia: retail e-commerce revenue forecast from 2017 to 2025 | Statistic," Statista, 2020. [Online]. Available: https://www.statista.com/statistics/280925/b2c-ecommerce-sales-in-indonesia/.

[3] https://www.cnnindonesia.com/ekonomi/20200707172450-92-521925/belanja-online-naik400-persen-saat-musim-corona

[4] Ratih Ayu Syafriza (2018), "Analisis Strategi Bersaing Bisnis E-commerce Studi Kasus Ppada PT. Bukalapak.com” Diunduh dari http://etd.repository.ugm.ac.id/ 
[5] Kotler, Philip. Dan G. Armstrong. 2012. Prinsip-prinsip Pemasaran. Edisi Keduabelas. Jilid 1. Penerbit Erlangga. Jakarta.

[6] Lupiyoadi, Rambat. dan A. Hamdani. 2011. Manajemen Pemasaran Jasa. Edisi Kedua. Salemba Empat. Jakarta.

[7] P. Kotler and K. L. Keller, "Marketing Management," 15e ed., B. Sabran, Ed. Edinburgh Gate: Pearson Education Limited, 2016.

[8] M. Konečnik Ruzzier, M. Ruzzier, and R. Hisrich, "Value, satisfaction and customer's loyalty,” Mark. Entrep. SMEs, no. November, pp. 21-36, 2014.

[9] Griffin Jill, Customer's loyalty:Menumbuhkan dan Mempertahankan Kesetiaan Pelanggan, 2nd ed. Erlangga, 2005.

[10] Yoga Saputra, Retno Setyorini, ST., MM. 2015. "Pengaruh Kualitas Pelayanan Service Motor Terhadap Kepuasan Pelanggan Pada Gti Motor". ISSN : 2355-9357 e-Proceeding of Management : Vol.2, No.3 Desember 2015 | Page 3660.

[11] Ratnasari, R.T., dan M.H. Aksa. 2011. Teori dan Kasus Manajemen Pemasaran Jasa. Ghalia Indonesia. Bogor.

[12] Kriyantono, Rachmat. 2008. Public Relations Writing Media Public Relations, Membangun Citra Korporat. Penerbit Kencana. Jakarta

JURNAL ILMIAH ELEKTRONIKA DAN KOMPUTER Vol. 13, No. 2, Desember $2020: 158-168$ 